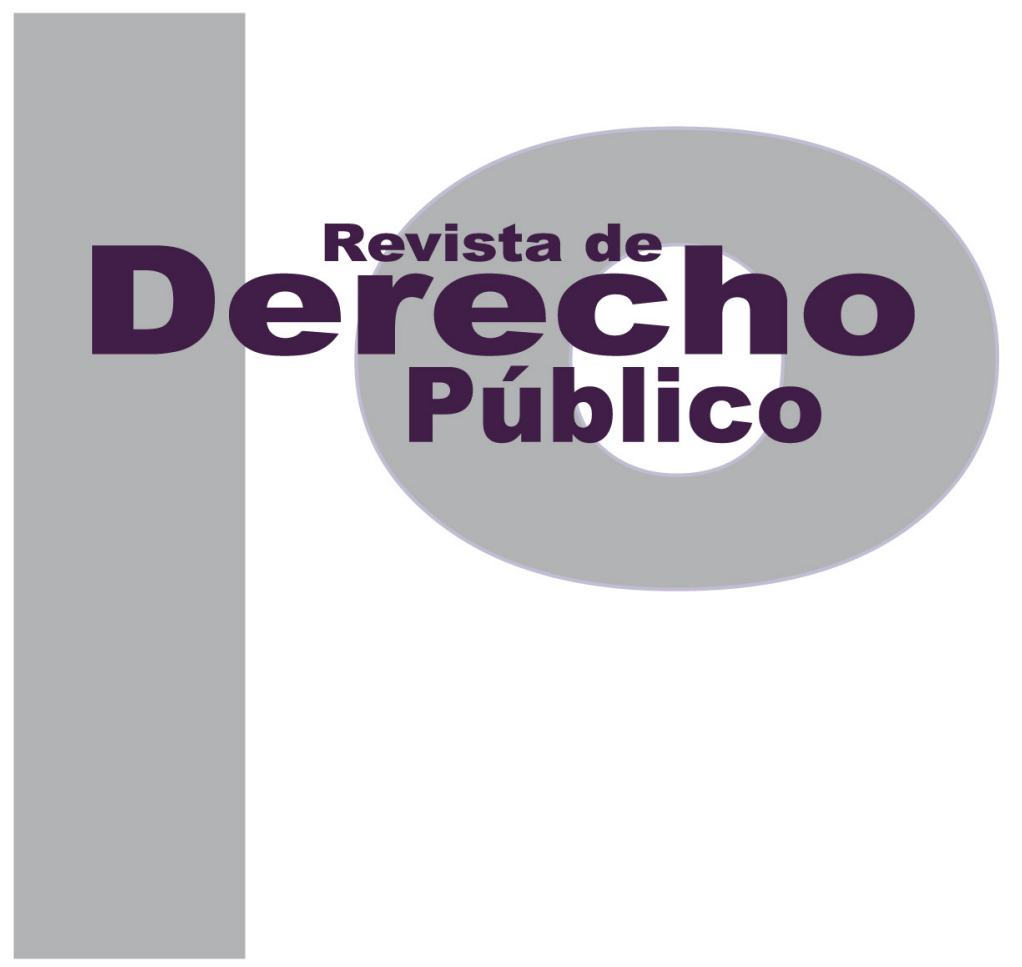

\title{
LA AUSENCIA DE RÉGIMEN DE TRANSICIÓN EN LA LEY 797 DE 2003 Y SU EVENTUAL INCONSTITUCIONALIDAD
}

\author{
Carlos Alberto Chamat Duque
}

Artículo de reflexión

DOI: http://dx.doi.org/10.15425/redepub.36.2016.01

Universidad de los Andes

Facultad de Derecho

Rev. derecho publico No. 36

enero - junio de 2016. e-ISSN 1909-7778 


\section{La ausencia de régimen de transición en la Ley 797 de 2003 y su eventual inconstitucionalidad}

Resumen

Dentro del sistema pensional colombiano, el régimen de prima media con prestación definida ha sido objeto de reformas legales que han modificado las condiciones para consolidar el derecho a la pensión de vejez por parte de los afiliados a este régimen.

En este contexto, al no existir disposición normativa que consagre la obligatoriedad del establecimiento de regímenes de transición en las reformas legales que afecten la causación del derecho a la pensión de vejez en el régimen de prima media con prestación definida, se hace necesario que, desde la dogmática jurídica y acudiendo a los principios que informan el derecho de la seguridad social en Colombia, se exponga la necesidad de la obligatoriedad jurídica del establecimiento de regímenes de transición en este ámbito, en orden a salvaguardar las expectativas legítimas de los afiliados al sistema pensional colombiano a través del mencionado régimen.

Palabras clave: régimen de transición, seguridad jurídica, expectativas legítimas, derechos adquiridos, derechos eventuales.

\section{The absence of a transitional regime in the Law 797 of 2003 and its eventual unconstitutionality}

\section{Abstract}

The Colombia Pension System, called, "Average Premium” with defined-benefit, has been subjected to different regulatory reforms. These changes affect seriously future old age pensioners with pension rights since their expectations of pension remuneration are difficult to achieve. In this particular context, there is no any Social Policy related to this transitional arrangement. Social guidelines must be included in the General Pension Scheme in order to enforce to obey which has been set up on the particular pension plan. It is peremptory and convenient to observe the principles that support the Social Security Law in Colombia to avoid interfering with pensioners' rights and also to protect them against poor living conditions when they retire.

Keywords: pension system, social security law, social policy, expectations of pension.

\section{A ausência de regime de transição na lei 797 de 2003 e sua eventual inconstitucionalidade Resumo}

Dentro do sistema de aposentadoria colombiano, o regime de prêmio médio com prestação definida tem sido objeto de reformas legais que têm modificado as condições para consolidar o direito à aposentadoria de velhice por parte dos afiliados a este regime.

Neste contexto, ao não existir disposição normativa que consagre a obrigatoriedade do estabelecimento de regimes de transição nas reformas legais que afetem a causação do direito à aposentadoria de velhice no regime de prêmio médio com prestação definida, se faz necessário que, desde a dogmática jurídica e acudindo aos princípios que informam o direito da seguridade social na Colômbia, se exponha a necessidade da obrigatoriedade jurídica do estabelecimento de regimes de transição neste âmbito, em ordem a salvaguardar as expectativas legítimas dos afiliados ao sistema de aposentadoria colombiano através do mencionado regime.

Palavras-chave: regime de transição, seguridade jurídica, expectativas legítimas, direitos adquiridos, direitos eventuais. 


\title{
La ausencia de régimen de transición en la Ley 797 de 2003 y su eventual inconstitucionalidad*
}

\author{
Carlos Alberto Chamat Duque**
}

\begin{abstract}
SUMARIO
Introducción - I. NATURALEZA JURÍDICA DEL RÉGIMEN DE TRANSICIÓN - A. Jurisprudencia sobre el régimen de transición del artículo 36 de la Ley 100 de 1993 - B. Los regímenes de transición en las reformas pensionales: ¿Un derecho per se? - C. El principio de progresividad en el régimen de transición - II. TRÁNSITOS LEGISLATIVOS PENSIONALES POSTERIORES A LA LEY 100 DE 1993 - A. Fundamentos constitucionales para la obligatoriedad del establecimiento de regímenes de transición en reformas pensionales - B. La omisión legislativa relativa en la no inclusión de régimen de transición en la Ley 797 de 2003 - III. CONCLUSIONES - Referencias.
\end{abstract}

* Cómo citar este artículo: Chamat Duque, C. A. (Junio, 2016). La ausencia de régimen de transición en la Ley 797 de 2003 y su eventual inconstitucionalidad. Revista de Derecho Público, (36). Universidad de los Andes (Colombia). DOI: http://dx.doi.org/10.15425/redepub.36.2016.01

** Abogado titulado por la Universidad de San Buenaventura, seccional Medellín; especialista en Derecho Laboral y Seguridad Social de la Universidad del Rosario; magíster en Derecho con énfasis en Derecho Público de la Universidad ICESI de Cali (VaIle); actualmente, abogado litigante en el área de Derecho Público. Correo: advocatusrs6@hotmail.com 
Introducción

Finalizado el año 2014, y en aplicación del parágrafo transitorio número $4^{\circ}$ del artículo $1^{\circ}$ del Acto Legislativo 01 de 2005, cesó la vigencia en el tiempo del régimen de transición ${ }^{1}$ establecido en el artículo 36 de la Ley 100 de 1993, disposición normativa que permitió la aplicación de normas pensionales más favorables para aquellos afiliados al régimen de prima media con prestación definida que con anterioridad a la entrada en vigencia del Sistema General de Pensiones eran beneficiarios de normas pensionales, en principio, más beneficiosas que las establecidas en la Ley 100 de 1993.

En el anterior contexto, el presente artículo se constituye en un escrito de reflexión sobre la exigibilidad jurídica del establecimiento de regímenes de transición en toda reforma normativa que modifique las condiciones y requisitos para acceder a la pensión de vejez, reflexión motivada por la corroboración de la no inclusión de régimen de transición alguno en la Ley 797 de 2003, norma mediante la cual se modificaron los requisitos sustanciales originariamente consagrados en el régimen general de pensiones de la Ley 100 de 1993 para acceder a dicha pensión.
Ante esta situación, en el presente escrito se plantea la problemática de la eventual inconstitucionalidad por omisión legislativa relativa de las reformas pensionales en las cuales el legislador colombiano omita el establecimiento de un régimen de transición, y cuyo ejemplo paradigmático, para los efectos de este artículo, estará constituido por la Ley 797 de 2003.

Para el desarrollo de la presente reflexión, en una primera parte se abordará la naturaleza jurídica del régimen de transición como un instituto jurídico respecto del cual el órgano legislativo, en virtud de la cláusula general de competencia y de la libertad de configuración legislativa que le asiste, se encuentra en la libertad de establecerlo o no establecerlo en las reformas legales, para posteriormente hacer énfasis en la importancia que dicha figura legal adquiere en el ámbito pensional, aspecto en el cual se hará especial consideración de los pronunciamientos jurisprudenciales de la Corte Constitucional colombiana sobre la materia.

En una segunda parte, y en atención a las múltiples diferencias interpretativas que existen respecto a la vigencia en el tiempo, beneficiarios y efectos jurídicos del artículo 36 de la Ley 100 de 1993, se analizarán las consecuencias jurídicas que razonablemente se pueden ex-

1. La disposición contenida en el artículo 36 de la Ley 100 de 1993 se ha convertido en el régimen de transición por antonomasia en el ámbito jurídico colombiano, habida cuenta de la trascendencia social que en materia pensional significó para la población económicamente activa la entrada en vigencia de la Ley 100 de 1993 en materia pensional, lo que significa que el mencionado régimen de transición es uno de tantos de los que pueden existir en las diversas leyes expedidas por el Congreso de la República de Colombia. 
traer de la jurisprudencia que la Corte Constitucional colombiana ha decantado en torno al régimen de transición contenido en el artículo 36 de la Ley 100 de 1993. Como consecuencia de ello, se planteará que existe la consolidación de un precedente jurisprudencial y constitucional sobre la temática del régimen de transición pensional, respecto del cual es plausible sostener la obligatoriedad jurídica del establecimiento de regímenes de transición en toda reforma pensional que modifique los requisitos para acceder a la pensión de vejez en el régimen de prima media con prestación definida.

En la tercera parte del artículo, previo el planteamiento consistente en que existen suficientes argumentos para considerar que la obiter dicta y el decisum de la jurisprudencia constitucional sobre el régimen de transición de la Ley 100 de 1993 son fuente formal del derecho y que como tal vinculan al legislador colombiano en las sucesivas reformas pensionales, se expondrán las razones jurídicas que permiten sostener la existencia, en cabeza de los afiliados al sistema pensional del régimen de prima media con prestación definida, de derechos económicos, sociales y culturales de carácter prestacional a que en toda reforma pensional en la que se afecten los requisitos para acceder a la pensión de vejez se establezca un régimen de transición, independientemente del contenido y los criterios que finalmente sean considerados por el legislador para delimitar los beneficiarios del mencionado régimen.

La única reforma pensional realizada a la Ley 100 de 1993 respecto de las condiciones para acceder a la pensión de vejez en el régimen de prima media con prestación definida será abordada en el capítulo cuatro, en el cual el lector detectará cómo, de manera inopinada, la Ley 797 de 2003 cambió abruptamente las condiciones y requisitos exigidos para la causación de la pensión de vejez originariamente plasmadas en la Ley 100 de 1993, sin que al efecto se estableciera régimen de transición alguno, consolidándose de esta manera una situación normativa contraria a lo que el principio de progresividad en materia de seguridad social aconsejaba implementar.

En el quinto capítulo se planteará la consecuencia lógica que se deriva de la tesis de la obligatoriedad del establecimiento de regímenes de transición en toda reforma pensional que afecte la causación de la pensión de vejez, constituida en el planteamiento de la inconstitucionalidad por omisión legislativa relativa que se predica de la Ley 797 de 2003 al omitir establecer un régimen de transición pensional que respetara las expectativas legítimas de los afiliados al régimen de prima media con prestación definida, que para la fecha de entrada en vigencia de dicha norma ( 29 de enero de 2003) se encontraban próximos a pensionarse o tenían expectativas legítimas de adquirir el derecho a la pensión de vejez, a la luz de los postulados originariamente contenidos en la Ley 100 de 1993 respecto de dicha prestación económica.

Finalmente, en el capítulo sexto se concluirá que, no obstante ser necesario el establecimiento de regímenes de transición en toda re- 
forma pensional que afecte un derecho social de tan alta trascendencia como el derecho a la pensión de vejez, los regímenes de transición en esta materia continúan siendo un campo propicio para la subjetividad del legislador colombiano, mientras no se establezcan criterios que consulten ámbitos que trasciendan las facetas jurídicas y políticas en orden al establecimiento equitativo y objetivo de las variables a considerar al momento de establecer el contenido y desarrollo de un régimen de transición pensional, de donde resultará la necesidad de consultar factores económicos, sociales y culturales para su establecimiento. En dicho sentido se harán planteamientos propios de la sociología jurídica que permitan actualizar las potenciales contribuciones que esta parcela del conocimiento jurídico está en capacidad de aportar al campo del derecho de la seguridad social.

\section{NATURALEZA JURÍDICA DEL RÉGIMEN DE TRANSICIÓN}

Desde la perspectiva del derecho positivo, una de las características inherentes al estudio de la norma jurídica ha sido la problemática de la vigencia de la ley en el tiempo (Nieto, 2011, p. 43). Al ser la creación legislativa una obra histórica y estar sujeta al cambio (Kelsen, 2010, p. 35), el principio de la seguridad jurídica, entendiendo por este la permanencia de la ley en el tiempo, se relativiza para dar cabida a las reformas legales, sin que ello quiera decir que las modificaciones normativas puedan ser arbitrarias y que en consecuencia sea viable que mediante estas se desconozcan las expectativas que los destinatarios de una norma jurídica específica empezaron a cultivar a través del tiempo.

Entonces, al ser los cambios normativos una de las características propias de la ley positiva, todo ordenamiento jurídico que se precie de ser civilizado y pretenda gozar de legitimidad estará irrevocablemente llamado a establecer un mínimo de beneficios y tratamientos especiales para aquellos sujetos que, en virtud de un cambio normativo, repentinamente puedan encontrarse en una situación legal desfavorable en relación con la situación jurídica de que venían disfrutando con anterioridad al tránsito legislativo que modificó o derogó la norma en cuestión.

Si bien es cierto los destinatarios de la norma jurídica no son titulares del derecho a que esta no sea modificada, también lo es que el legislador, en la reglamentación de las relaciones jurídicas de los asociados, debe procurar bajo criterios de razonabilidad y proporcionalidad que los tránsitos legislativos sean lo menos drásticos posibles, en atención, precisamente, a que los destinatarios de la norma aspiran y esperan que tome decisiones legislativas razonables que alteren lo menos posible las expectativas que la ley derogada había creado en su momento. Lo anterior sin perjuicio de los costos políticos que para el proponente de un proyecto de ley pueda representar el modificar súbitamente una situación jurídica respecto de la cual los beneficiarios gozaban de unas expectativas, y cuyo caso paradigmático, al me- 
nos mediáticamente y en lo que a la República de Colombia concierne, se encuentra constituido por las normas que establecen los requisitos para acceder a la pensión de vejez, habida cuenta que la consolidación de este derecho prestacional es de carácter paulatino y progresivo al requerir la secuencial acreditación de cotizaciones al sistema, lo mismo que el cumplimiento de la edad mínima requerida.

Dicha problemática de la protección jurídica que merecen las expectativas se hace más evidente en tanto mayores y más importantes sean los derechos fundamentales involucrados en el cambio normativo, cuyos ejemplos por excelencia se encuentran representados por las áreas del derecho penal y el derecho de la seguridad social pensional, áreas jurídicas en las cuales un cambio normativo puede significar, ora la libertad del condenado, ora el surgimiento del derecho a la pensión de vejez del afiliado al Sistema General de Pensiones. ${ }^{2}$

Entonces, para regular las complejas situaciones que surgen con la aplicación de la ley en el tiempo y respecto a los tránsitos legislativos en materia penal y pensional es que han surgido dispositivos jurídicos tales como el principio de favorabilidad, el principio de la condición más beneficiosa, la regla general de la irretroactividad de la ley y los regímenes de transición, por nombrar solo algunos, los cuales se encuen- tran encaminados a atemperar el rigor característico del antiguo pero vigente aforismo jurídico que reza "dura lex sed lex" (Ossorio, 1999, p. 367), por cuanto mediante dichos dispositivos normativos se reconocen los impactos negativos que, por regla general, un cambio legislativo acarrea a sus destinatarios.

De esta manera, y en lo que se refiere a la aplicación de las leyes pensionales en el tiempo, tanto la doctrina (Jaramillo, 2013, p. 34) como la jurisprudencia han definido las diversas situaciones legales en las cuales se encuentran los destinatarios de las normas pensionales al momento de estas entrar en vigencia, y es allí en donde adquieren relevancia las categorías jurídicas de los derechos adquiridos, las meras expectativas y las expectativas legítimas, por mencionar solo algunas de las principales en la materia.

De tal trascendencia son entonces los derechos constitucionales fundamentales implicados en toda reforma legal y constitucional en materia pensional, que en el actual estado de evolución de la ciencia jurídica colombiana resulta inconcebible desde el ámbito jurídico, e inconveniente desde el ámbito político, plantear la puesta en vigencia de una ley pensional que desconozca lo que en dicha ciencia se ha dado en denominar las "expectativas legítimas" de los afiliados al sistema pensional.

2. El actual Código Penal colombiano contenido en la Ley 599 de 2001 establece en su artículo $6^{\circ}$ : “La ley permisiva o favorable, aun cuando sea posterior se aplicará, sin excepción, de preferencia a la restrictiva o desfavorable. Ello también rige para los condenados", disposición esta que goza de la misma naturaleza práctica de los regímenes de transición expresamente establecidos en la ley, con la diferencia de que aquí se trata de una especie de régimen de transición "hacia el futuro". 
Respecto al mantenimiento de las expectativas legítimas creadas en los afiliados al sistema pensional del régimen de prima media con prestación definida, y en tratándose de la reforma pensional general introducida con la Ley 100 de 1993, en lo que concierne al periodo comprendido entre el primero de abril de 1994 hasta los actuales momentos, dicha protección ha estado parcialmente regulada por el mencionado artículo 36 de la Ley 100 de 1993. El adjetivo de parcialmente regulada se entiende en la medida en que se identifiquen los tres grupos poblacionales a los cuales está dirigida la Ley 100 de 1993 en materia pensional, a saber:

A. En primer lugar, la Ley 100 de 1993 está dirigida a los afiliados al régimen de prima media que con anterioridad a su entrada en vigencia se encontraban regidos bajo normas distintas, las cuales, por regla general, eran más favorables en cuanto a las condiciones necesarias para la causación del derecho a la pensión de vejez. Precisamente por ello se estableció a su favor el régimen de transición contenido en su artículo 36, con la finalidad de que las condiciones pensionales de estos sujetos no desmejoraran con la nueva ley.

B. En segundo lugar, la Ley 100 de 1993 estuvo destinada a regir la situación pensional de aquellos afiliados al régimen de prima media con prestación definida que, igualmente, antes de su entrada en vigencia estaban cobijados por regímenes distintos al régimen general por ella establecido, pero que por diversas razones no lograron ser beneficiarios del régimen de transición del artículo 36 y, por ende, quedaron sujetos en materia pensional a esta nueva ley en su totalidad.

C. En tercer lugar, la Ley 100 de 1993 estuvo destinada a los nuevos afiliados al sistema pensional que ingresaron con posterioridad al 1 de abril de 1994, en tratándose de trabajadores del sector privado, y con posterioridad al 30 de junio de 1995, en tratándose de servidores públicos.

De esta manera, el presente texto enfocará la atención en el trato normativo recibido por el tercer grupo poblacional al que precedentemente se hizo alusión, respecto de quienes la Ley 797 de 2003, al reformar aspectos sustanciales de la pensión de vejez regulada originalmente en la Ley 100 de 1993, no tuvo la previsión de establecer un régimen de transición a su favor, tal como se verá en las líneas subsiguientes.

\section{A. Jurisprudencia sobre el régimen de transición del artículo 36 de la Ley 100 de 1993}

Al ser el derecho positivo un derecho legislado, este se encuentra sujeto a las vicisitudes políticas que cada cierto tiempo suelen ocurrir en el devenir de toda democracia moderna. En estas condiciones, las reformas normativas se constituyen en la mejor manifestación de la dinámica jurídica por cuanto la norma legal, si 
bien es cierto que rige y se expide con ánimo de permanencia, siempre estará sujeta a posteriores modificaciones o supresiones según las circunstancias políticas, económicas o sociales del momento.

Al ser el derecho a la pensión de vejez en el régimen de prima media una prestación económica que se configura con el sucesivo cumplimiento de dos requisitos en el tiempo, como son la edad mínima de pensión y la densidad de semanas o tiempo de servicios mínimos requeridos, han sido las altas Cortes colombianas las corporaciones judiciales que mediante su jurisprudencia han definido los contornos propios del derecho a la pensión de vejez en lo que respecta a las reformas legislativas que alteran o modifican los requisitos para su causación. En este aspecto, la honorable Corte Suprema de Justicia, Sala de Casación Laboral, ha sido clara en señalar que los regímenes de transición en materia pensional únicamente son viables en tratándose de las pensiones de vejez, en atención a que

el régimen de transición en las pensiones de vejez se da porque es viable considerar la mayor o menor aproximación a la edad y al total de cotizaciones exigidas bajo un régimen, para determinar el grupo de la población que eventualmente puede acceder a esa prestación (por el transcurso del tiempo -hecho determinable-, ya para completar cierta edad o para sumar un período de cotizaciones); mientras que en la de invalidez, por ejemplo, obedece a contingencias improbables de predecir, y por ende, no regulables por un régimen de transición. (CSJ, 15 feb. 2011, C. E. Molina). [Cursivas fuera de texto].

En el discurrir de la Corte Suprema de Justicia, la problemática de la ausencia de régimen de transición respecto de las pensiones de sobrevivientes y de invalidez da lugar a que en estas se haga uso del principio de la condición más beneficiosa, mas no así respecto de la pensión de vejez, por cuanto desde la doctrina de la Sala Laboral de dicho tribunal:

La condición más beneficiosa, tiene adoctrinado la Sala, entra en juego, no para proteger a quienes tienen una mera o simple expectativa, pues para ellos la nueva ley puede modificarles el régimen pensional, sino a un grupo de personas, que si bien no tienen un derecho adquirido, se ubican en una posición intermedia habida cuenta que poseen una situación jurídica y fáctica concreta, verbigracia, haber cumplido en su integridad la densidad de semanas necesarias que consagraba la ley derogada. A ellos, entonces, se les debe aplicar la disposición anterior, es decir, la vigente para el momento en que las satisfizo. En ese horizonte, ha enseñado esta Corporación que tratándose de derechos que no se consolidan por un solo acto sino que suponen una situación que se integra mediante hechos sucesivos, hay lugar al derecho eventual, que no es definitivo o adquirido mientras no se cumpla la última condición, pero que sí implica una situación concreta protegida por la ley, tanto en lo que atañe al acreedor como al deudor, por lo que supera la mera o simple expectativa. (cSJ, 25 
jul. 2012, C. E. Molina y L. G. Miranda). [Cursivas fuera de texto].

Por su parte, sobre el régimen de transición, la decantada jurisprudencia de la honorable Corte Constitucional ha hecho uso de los conceptos jurídicos meras expectativas, expectativas legítimas y derechos adquiridos, en orden a darle alcance y sentido a la institución del régimen de transición en materia pensional. Al respecto, en la Sentencia C-789 de 2002 la Corte Constitucional, al decidir en sede de constitucionalidad la exequibilidad de una norma que excluía del régimen de transición a las personas de determinada edad que decidieran voluntariamente cambiarse de sistema, sentó el precedente de las Ilamadas expectativas legítimas, concepto que posteriormente entraría a hacer parte integrante de la obiter dicta de todas los problemas jurídicos relacionados con el régimen de transición. Adicionalmente, en los considerandos de la Sentencia T-754 de 2012 señala:

Con todo, pese a que los derechos adquiridos deben respetarse sin lugar a discusión y las meras expectativas pueden truncarse como consecuencia de cambios de legislación o decisiones administrativas, en materia de reconocimiento de derechos pensionales la Corte Constitucional ha elaborado una sólida jurisprudencia de protección de aquellas expectativas próximas a realizarse. La jurisprudencia constitucional ha establecido una diferencia inequívoca entre las meras expectativas y aquellas expectativas legítimas y previsibles de adquisición de un derecho, para concluir que mientras las primeras no son objeto de protección constitucional, las segundas gozan de un privilegio especial proveniente de la carta.

Los mecanismos de protección de las expectativas legítimas de adquisición de derechos sociales se fundan en el reconocimiento de la calidad de los aspirantes. En efecto, estos mecanismos protegen las esperanzas de personas que ingresaron a trabajar con anticipación considerable, que han cotizado al sistema por lo menos la mitad de su vida laboral y han cifrado parte de su futuro en un retiro próximo, con el anhelo de disfrutar del mismo hasta una edad probable promedio. No son, pues, las expectativas lejanas de quienes apenas se vinculan al mercado laboral, empiezan a cotizar al régimen de pensiones o guardan energías para diseñar su retiro en un futuro incierto. (26 sep. 2012, J. I. Pretelt Chaljub).

Más recientemente, en Sentencia C-853 de 2013, la honorable Corte Constitucional se pronunció sobre esta temática en el siguiente sentido:

En varias ocasiones esta Corporación ha estudiado el alcance de la protección a los derechos adquiridos en la Carta, y ha especificado su diferencia con las expectativas legítimas. Los derechos adquiridos, han sido definidos como aquellos que se consolidan cuando se han cumplido todos los presupuestos normativos exigidos bajo el imperio de una ley, para 
que se predique el nacimiento de un derecho subjetivo. Configurado el derecho bajo las condiciones fijadas por una norma, su titular puede exigirlo plenamente, porque se entiende jurídicamente garantizado e incorporado al patrimonio de esa persona. El artículo 58 de la Carta, garantiza precisamente la protección constitucional de este tipo de derechos, al prohibir expresamente su desconocimiento o vulneración mediante leyes posteriores. Es por esto que el quebrantamiento de situaciones jurídicas consolidadas bajo la vigencia de una ley anterior, resulta contraria a la Constitución. Las expectativas legítimas, por su parte, suponen que los presupuestos exigidos bajo la vigencia de una ley para consolidar un derecho, no se han configurado, aunque "resulta probable que lleguen a consolidarse en el futuro, si no se produce un cambio relevante en el ordenamiento jurídico". Las expectativas legítimas, en consecuencia, no implican el nacimiento de un derecho, sino que suponen una probabilidad cierta de consolidación futura del correspondiente derecho, si se mantienen las condiciones establecidas en una ley determinada. De allí que se considere, en general, que tales expectativas pueden ser modificadas por el legislador en virtud de sus competencias, si ello se requiere para cumplir fines constitucionales. El legislador, por lo tanto, no está obligado en principio a perpetuar las meras expectativas en el tiempo, dado que no son objeto en sentido estricto de la misma protección consagrada en el artículo 58 de la Carta Política para los derechos adquiridos. (27 nov. 2013, M. González). [Cursivas fuera de texto].
Abordando ahora el tema al tenor literal que informa el artículo 36 de la Ley 100 de 1993, el régimen de transición pensional colombiano establecido en dicha norma se ofrece de fácil inteligencia para el operador jurídico, dado que su texto es claro en señalar los requisitos que deben cumplir los afiliados al sistema pensional que al momento de entrada en vigencia de la Ley 100 de 1993 (1 ${ }^{\circ}$ de abril de 1994 para los trabajadores del sector privado) aspiraban a conservar las condiciones pensionales que antes los cobijaban.

El tenor literal del mencionado régimen de transición (artículo 36) es como sigue:

La edad para acceder a la pensión de vejez de las personas que al momento de entrar en vigencia el sistema tengan treinta y cinco (35) o más años de edad si son mujeres o cuarenta (40) o más años de edad si son hombres, o quince (15) o más años de servicios cotizados, será la establecida en el régimen anterior al cual se encuentren afiliados.

De esta manera, entonces, si bien es cierto existen criterios jurídicos según los cuales ostenta la categoría de derecho adquirido el hecho de haber sido inicialmente beneficiario del régimen de transición pensional, en el sentido consistente en que al haber estado cubierto por dicho régimen se adquiere per se el derecho a conservar tal situación jurídica de manera definitiva e indefinida en el tiempo, tal como en su momento lo prohijó la sentencia T-168 de 2009 que posteriormente fuera declarada nula por el Auto 009 de 2010 por ha- 
ber contrariado la jurisprudencia de la propia Corte Constitucional, también es cierto que la posición jurisprudencial dominante al respecto y proveniente de la Corte Constitucional ha sido que los beneficiarios de un régimen de transición gozan de ese beneficio mientras la misma norma que lo establezca, y las posteriores reformas jurídicas, se los permita, bajo el entendido consistente en que los afiliados al sistema pensional no tienen derecho a que su situación de ser beneficiarios del régimen de transición sea intangible en el tiempo y con perjuicio de las ulteriores reformas jurídicas que puedan presentarse. La única situación jurídica intangible, en dicho sentido, está constituida por la adquisición del derecho a la pensión de vejez, el cual se convierte en un derecho adquirido que como tal debe ser respetado por las ulteriores reformas pensionales que puedan llevarse a cabo por parte del legislador.

\section{B. Los regímenes de transición en las reformas pensionales: ¿Un derecho per se?}

Estatuido dentro de la fórmula jurídico-política del Estado social de derecho, el ordenamiento jurídico colombiano encuentra uno de sus pilares fundamentales en el principio de la legalidad, según el cual el imperio de la ley es el sustrato esencial del Estado colombiano, el que se enmarca dentro de un modelo democrático en donde prima el bien común manifestado en la expedición de leyes de carácter general y abstracto.
Ahora, si bien es cierto que toda ley debe expedirse con el ánimo de permanencia en aras de que se garantice su eficacia y vigencia en la sociedad, también es cierto que por la naturaleza política de las funciones legislativas encomendadas al Congreso de la República, el órgano legislativo, en virtud de la cláusula general de competencia, se encuentra legitimado para crear, modificar y extinguir normas jurídicas. Lo anterior en consonancia con la libertad de configuración legislativa, la cual permite que en materia de normas jurídicas se presente un dinamismo que flexibiliza el ordenamiento jurídico, el cual, no pocas veces, entra en contradicción con las denominadas expectativas legítimas y la confianza legítima que los destinatarios de la ley depositan en esta.

Así las cosas, de la propia dinámica legislativa surge una inexorable contraposición entre el principio de la seguridad jurídica que debe regir la producción normativa en orden a que esta sea tomada "en serio", y los fundamentos políticos inmersos en la función legislativa que hacen que el derecho positivo sea cambiante por cuanto no es posible concebir, al menos desde una visión democrática y pragmática, la existencia de un ordenamiento con normas pétreas.

Para justificar la verdad de la aseveración anterior, basta tomar como referencia el hecho consistente en que las Constituciones políticas de los países occidentales, que se supone son las normas jurídicas que mayor vocación de permanencia deben de poseer en una sociedad, admiten, en su mayoría, la posibilidad de reformas constitucionales. 
Decantadas las anteriores reflexiones, y en lo que respecta al panorama pensional colombiano del régimen de prima media con prestación definida, se comprende claramente el impacto y los costos políticos que representaría la ausencia total de regímenes de transición al momento de operar un tránsito legislativo que modifique dicho derecho social, esto es, el derecho a la pensión, el cual se constituye en una temática que, sin hesitación alguna, es una de las más sensibles en materia de políticas públicas del Estado colombiano, precisamente por las repercusiones sociales que representa una decisión política que, ora incluya, ora excluya, a un amplio rango de la población colombiana dentro o fuera de la cobertura del derecho de la seguridad social pensional, de contera se verá reflejada igualmente en el campo de la protección en salud por la inescindible relación entre la pensión y los beneficios que de esta se derivan en materia de afiliación al régimen contributivo en salud.

En el anterior contexto se enmarca entonces la importancia de los regímenes de transición que, si bien es cierto también tienen aplicación en ámbitos distintos al de la seguridad social pensional, en lo que a Colombia respecta se puede aseverar sin duda alguna que la institución jurídica del régimen de transición se encuentra representada, por antonomasia, en el régimen de transición pensional consagrado en el artículo 36 de la Ley 100 de 1993.

Conduciendo el presente análisis al ámbito legislativo, cabe ahora poner de presente la problemática consistente en la obligatoriedad o discrecionalidad que le asiste al órgano le- gislativo colombiano en relación con la adopción o no adopción de regímenes de transición al momento de efectuar reformas pensionales que afecten la causación del derecho a la pensión de vejez en el régimen de prima media con prestación definida.

En principio, y en consonancia con los pronunciamientos de la honorable Corte Constitucional colombiana, el régimen de transición es una concesión del legislador puesto que el Congreso de la República es libre de establecerlo o no. Refiriéndose al régimen de transición, en Sentencia C-754 de 2004 el máximo órgano constitucional colombiano señaló:

Se trata de un derecho ex - lege porque nace de una norma que expresamente lo establece y que señala criterios razonables para gozar de la excepcionalidad. Una vez entre en vigencia la norma que establece el régimen transitorio, las personas que reúnen los requisitos para adquirirlo consolidan una situación jurídica concreta que no puede ser menoscabada. Es además un auténtico derecho subjetivo que le da a su titular el derecho a que se le reconozca la prestación en las condiciones establecidas en la normatividad anterior y a acudir ante la jurisdicción en caso de incumplimiento. Como además los derechos provenientes de la seguridad social son irrenunciables, (artículos 48 y 53 C.P.), con mayor razón se requiere un régimen de transición. (CConst., 10 ago. 2004, A. Tafur).

Aunque no existe en Colombia disposición constitucional ni legal que establezca la obligatorie- 
dad del establecimiento de regímenes de transición, en tratándose de reformas que versen sobre la causación del derecho a la pensión de vejez en el régimen de prima media se constituye en un criterio relevante el expresado por la Corte Constitucional al señalar que, respecto de tránsitos legislativos atinentes a derechos irrenunciables como el de la seguridad social, el régimen de transición se convierte en una necesidad tanto jurídica como política.

En su discurrir filosófico, precisamente la Corte Constitucional ha llamado la atención respecto de las condiciones que deben coexistir en todo tránsito legislativo, y ha señalado que “tal como se expresó en la Sentencia C-789 de 2002, cualquier tránsito legislativo que afecte expectativas legítimas debe consultar parámetros de justicia y equidad y está sujeto a los principios de razonabilidad y proporcionalidad" (C-754/2004, A. Tafur), lo que denota que si bien es cierto el legislador colombiano cuenta, en principio, con libertad para señalar los criterios con base en los cuales se determinarán los sujetos beneficiarios del régimen de transición, en tratándose de una reforma al sistema pensional del régimen de prima media con prestación definida no puede sustraerse legítimamente de establecer un régimen de transición mediante el cual se protejan las expectativas legítimas de aquellas personas afectadas con la vigencia de la nueva ley.

Es precisamente en esas abstenciones legislativas en donde radican las omisiones legislativas propicias para formular un juicio de inconstitucionalidad en contra de la norma pensional que reforme los requisitos para acceder a la pensión de vejez sin establecer, al respecto, el más elemental régimen de transición.

De no acogerse la argumentación precedentemente expuesta, el régimen de transición del artículo 36 de la Ley 100 de 1993 solo admitiría ser enfocado desde dos ópticas opuestas, esto es, observarlo como una dádiva del Congreso de la República hacia un significativo grupo de afiliados al sistema pensional del régimen de prima media con prestación definida, por cuanto les permitió conservar las condiciones pensionales más favorables en comparación con las condiciones impuestas mediante la Ley 100 de 1993, o enfocarlo como una norma contraria a la lógica de la eficiencia financiera que debe presidir la administración del sistema de seguridad social pensional, dado que con la viabilidad jurídica que se tenía de omitir establecer el régimen de transición que finalmente se incluyó en el artículo 36 de la Ley 100 de 1993 se perdió una oportunidad histórica de solventar las arcas del Estado colombiano, por las consabidas cargas económicas inherentes a un pasivo pensional que con el establecimiento del mencionado régimen de transición se aumentó de manera exponencial al aumentar el número de afiliados con derecho a la pensión de vejez.

Sobra señalar que fue precisamente dicha carga económica del pasivo pensional aumentado a través del dispositivo del régimen de transición consagrado en el artículo 36 de la Ley 100 de 1993, una de las razones políticas que motivaron la expedición del Acto Legislativo 01 de 2005 mediante el cual se le impusieron lí- 
mites a la vigencia en el tiempo del mencionado régimen de transición.

\section{El principio de progresividad en el régimen de transición}

En materia de derechos económicos, sociales y culturales, entre los cuales se enmarca el derecho a la seguridad social pensional, el principio de la progresividad ha sido continuamente abordado por la jurisprudencia de la Corte Constitucional, órgano judicial que ha conceptuado acerca de los alcances que este principio tiene en la materia, el cual se caracteriza principalmente por el hecho consistente en que, una vez alcanzado cierto grado de bienestar social a través del sistema jurídico, el ordenamiento legal colombiano no debe establecer medidas regresivas que afecten las pretéritas condiciones más favorables o más beneficiosas de que gozaban los afiliados del sistema pensional.

En Sentencia C-228 de 2011 el máximo tribunal constitucional colombiano tuvo oportunidad de señalar:

El mandato de progresividad implica que una vez alcanzado un determinado nivel de protección, la amplia libertad de configuración del legislador en materia de derechos sociales se ve restringida, al menos en un aspecto: todo retroceso frente al nivel de protección alcanzado es constitucionalmente problemático puesto que precisamente contradice el mandato de progresividad. Como los Estados pueden enfrentar dificultades, que pueden hacer imposible el mantenimiento de un grado de protección que había sido alcanzado, es obvio que la prohibición de los retrocesos no puede ser absoluta sino que debe ser entendida como una prohibición prima facie. Esto significa que, como esta Corte ya lo había señalado, un retroceso debe presumirse en principio inconstitucional, pero puede ser justificable, y por ello está sometido a un control judicial más severo. Para que pueda ser constitucional, las autoridades tienen que demostrar que existen imperiosas razones que hacen necesario ese paso regresivo en el desarrollo de un derecho social. (30 mar. 2012, J. C. Henao).

En este contexto, la problemática jurídica de la obligatoriedad o discrecionalidad del legislador en cuanto a la posibilidad de establecer o no establecer regímenes de transición en las reformas efectuadas a la pensión de vejez, dentro del régimen de prima media con prestación definida, quedaría superada siempre y cuando el establecimiento del régimen de transición del artículo 36 de la Ley 100 de 1993 se enfoque como una conquista jurídica que en las sucesivas reformas pensionales no debe ser obviada, so pena de incurrirse, por omisión legislativa, en medidas regresivas al privar injustificadamente de regímenes de transición a los afiliados al mencionado régimen, respecto de los cuales se modifiquen las normas que regían al momento de ingresar al sistema pensional en su calidad de afiliados.

De esta manera, entonces, si bien en primera instancia el principio de la progresividad en materia de seguridad social es abordado 
desde la perspectiva de los derechos adquiridos en relación con los afiliados al Sistema de Seguridad Social Pensional, no habría, en primera instancia, motivo para sostener que el principio de la progresividad no sea aplicable respecto del trato normativo que reciben las expectativas legítimas o las meras expectativas de los afiliados al sistema pensional en atención a que, precisamente, el régimen de transición es un dispositivo normativo que protege expectativas legítimas que en muchos casos serán el germen de futuros derechos pensionales adquiridos.

$Y$ es que, precisamente, tan importantes son las expectativas legítimas o las meras expectativas para la ciencia jurídica, que no solamente el derecho de la seguridad social colombiano contenido en la Ley 100 de 1993 las protege en su artículo 36. Basta observar cómo parcelas jurídicas distintas a la seguridad social, tales como la civil (Montoya, 2001, p. 35), igualmente prevén la protección legal de las expectativas al establecer, verbigracia, la protección jurídica del nasciturus, quien, por el hecho de la potencialidad que tiene de llegar a ser persona, se encuentra provisto de mecanismos jurídicos para salvaguardar sus expectativas de plenos derechos.

\section{TRÁNSITOS LEGISLATIVOS PENSIONALES POSTERIORES A LA LEY 100 DE 1993}

Señalada la existencia del régimen de transición de la Ley 100 de 1993, cabe indagar por las ulteriores modificaciones pensionales sufridas por dicha norma y por la existencia o inexistencia de regímenes de transición en tales reformas.

Si bien es cierto que la Ley 100 de 1993 en su versión original constituyó un punto de inflexión en la historia pensional colombiana al dividirla en un "antes" y un "después", también es cierto que sus reformas no han tenido el mismo impacto mediático que en su momento, y aún hoy, tiene la referida norma.

Materialmente y en el ámbito de su contenido, en lo que concierne al sistema pensional del régimen de prima media con prestación definida, la Ley 100 de 1993, al ser modificada por la Ley 797 de 2003, perdió, en esencia, las características que en su momento la definieron, para convertirse en un nuevo régimen pensional que no obstante seguir denominándose Ley 100 de 1993, lo único que conserva de esta es precisamente su denominación normativa, situación que no ha sido suficientemente puesta de presente entre los estudiosos del derecho pensional colombiano.

Resulta entonces plausible afirmar que, en virtud de las sucesivas y sustanciales reformas que ha sufrido la Ley 100 de 1993, en el campo pensional esta ha dejado de existir, o, cuando más, solo queda su nombre, bien sea que se trate de pensión de vejez, invalidez o sobrevivientes, habida cuenta que estas tres modalidades de pensión actualmente se rigen por lineamientos que son diametralmente opuestos a los establecidos en la primigenia Ley 100 de 1993. 
En lo que respecta a la pensión de vejez, la redacción original de la Ley 100 de 1993 establecía la consolidación de dicho derecho a favor de aquellas personas que, teniendo una densidad mínima de mil (1000) semanas cotizadas al sistema, tuviesen cincuenta y cinco (55) años de edad, en caso de ser mujer, o sesenta (60) años de edad, en tratándose de los hombres.

Dicha disposición normativa, que comenzó su vigencia el primero $\left(1^{\circ}\right)$ de abril de 1994 para los trabajadores del sector privado, y el treinta (30) de junio de 1995 para los servidores públicos de conformidad con el parágrafo del artículo 151 de la mencionada norma, fue flexible en el ámbito de su aplicación en lo que se refiere a la densidad de semanas cotizadas, puesto que al establecerse el régimen de transición de su artículo 36, las personas que al primero de abril de 1994 tuvieran 35 años de edad cumplidos, en tratándose de las mujeres, 40 años de edad cumplidos, en tratándose de los hombres, o quince años o más de servicios cotizados al sistema de pensiones independientemente del género al cual pertenecieren, fueron sujetos acreedores del beneficio consistente en que al momento de llegar a la edad pensional mínima consagrada en la ley, se les aplicaban las normas establecidas en el régimen anterior al cual se encontraban afiliadas. Dicho régimen anterior estuvo constituido, en el caso concreto de los trabajadores del sector privado, por el Decreto 758 de 1990 mediante el cual se aprobó el Acuerdo 049 de 1990 del Instituto de los Seguros Sociales, y respecto de los servidores públicos correspondió, entre otros, a los regímenes pensionales establecidos en la Ley 33 de 1985 o a la Ley 71 de 1988, por solo enunciar algunos, en atención a la multiplicidad de regímenes existente en el sector público con anterioridad a la entrada en vigencia de la Ley 100 de 1993.

Así las cosas, a su entrada en vigencia la Ley 100 de 1993 tuvo tres destinatarios específicos, entre los cuales se encontraban los nuevos afiliados al sistema pensional que ingresaron con posterioridad al 1 de abril de 1994, en tratándose de trabajadores del sector privado, y con posterioridad al 30 de junio de 1995, en el caso de los servidores públicos. Para estos dos grupos de afiliados la Ley 100 de 1993 en su versión primigenia estableció como requisitos para acceder a la pensión de vejez, el haber cumplido 55 años de edad -las mujeres- o 60 años de edad -los hombres-, y contar con una densidad de mil (1000) semanas cotizadas al sistema.

En este contexto, los sujetos de derecho anteriormente referidos empezaron a construir a través del tiempo unas expectativas de consolidar su pensión de vejez mediante el cumplimiento progresivo de los dos requisitos de edad y densidad de semanas exigidos por la Ley 100 de 1993 en su versión primigenia, esto es, sin sus posteriores reformas.

Ahora bien, el 29 de enero de 2003 entró a regir la Ley 797, norma jurídica mediante la cual se reformaron aspectos sustanciales en cuanto a los requisitos de semanas cotizadas necesarias para acceder a la pensión de vejez 
en el régimen de prima media con prestación definida, reforma legislativa que en su articulado omitió establecer régimen de transición alguno.

En lo que al presente artículo interesa, la Ley 797 de 2003 consagró:

Artículo $9^{\circ}$. Reglamentado parcialmente, Decreto Nacional 510 de 2003. El artículo 33 de la Ley 100 de 1993 quedará así:

Artículo 33. Requisitos para obtener la Pensión de Vejez. Para tener el derecho a la Pensión de Vejez, el afiliado deberá reunir las siguientes condiciones:

1. Haber cumplido cincuenta y cinco (55) años de edad si es mujer o sesenta (60) años si es hombre.

A partir del $1^{\circ}$ de enero del año 2014 la edad se incrementará a cincuenta y siete (57) años de edad para la mujer, y sesenta y dos (62) años para el hombre.

2. Haber cotizado un mínimo de mil (1000) semanas en cualquier tiempo.

A partir del $1^{\circ}$ de enero del año 2005 el número de semanas se incrementará en 50 y a partir del $1^{\circ}$ de enero de 2006 se incrementará en 25 cada año hasta llegar a 1.300 semanas en el año 2015.

Se tiene, así, que la Ley 797 de 2003, en materia pensional, más que reformar la Ley 100 de 1993 la sustituye, habida cuenta de las trascendentales y nuevas reglas que estableció para la causación del derecho a la pensión de vejez en el régimen de prima media con prestación definida.

\section{A. Fundamentos constitucionales para la obligatoriedad del establecimiento de regímenes de transición en reformas pensionales}

La problemática consistente en la obligatoriedad o discrecionalidad que le asiste al órgano legislativo en cuanto al establecimiento o no de un régimen de transición en reformas pensionales que modifiquen los requisitos para acceder a la pensión de vejez en el régimen de prima media con prestación definida quedaría fácilmente zanjada si se aborda desde la óptica del derecho positivo, por cuanto, como anteriormente se señaló, en los actuales momentos ni en la Constitución Política ni en la ley colombiana existe precepto normativo expreso que vincule al legislador colombiano en tal sentido.

De hecho, en la Constitución Política de 1991 el único artículo que menciona el concepto de régimen de transición es el $48^{\circ}$, reformado por el Acto Legislativo 001 de 2005, y lo hace en el sentido de ponerle límite en el tiempo a la vigencia del régimen de transición establecido en la Ley 100 de 1993 y demás normas que lo desarrollen. Así las cosas, no existe un mandato genérico que obligue al establecimiento de regímenes de transición en las reformas pensionales que modifiquen los requisitos de la causación de la pensión de vejez en el régimen de prima media. 
No obstante lo anterior, del estudio armónico del ordenamiento jurídico y del tenor del artículo $48^{\circ}$ de la Constitución Política de 1991 que reza: “El Estado, con la participación de los particulares, ampliará progresivamente la cobertura de la Seguridad Social que comprenderá la prestación de los servicios en la forma que determine la Ley", se desprende que una de las características inherentes al Sistema de Seguridad Social colombiano es la progresividad, particularidad que en términos de seguridad social adquiere el contorno de principio jurídico.

Ahora bien, habida cuenta que la eventual obligatoriedad del establecimiento de un régimen de transición en materia de reformas pensionales gozaría de las características propias de un derecho económico, social y cultural, por cuanto el legislador estaría en la obligación de desarrollarlo y atender el principio de progresividad, se dan las condiciones fácticas para aseverar que una vez establecido el régimen de transición en el Sistema General de Pensiones creado por la Ley 100 de 1993, en lo sucesivo, el legislador colombiano, en lo que respecta a las reformas pensionales, no podría desconocer ese "mínimo" establecido en su artículo 36, esto es, un específico régimen de transición para el tránsito legislativo que significó su entrada en vigencia. Al respecto es importante la interpretación que del principio de progresividad hizo la Corte Constitucional en su Sentencia C-228 de 2011:

El principio de progresividad y la prohibición de no regresividad son componentes esen- ciales de la garantía de los derechos económicos, sociales y culturales. De conformidad con esos dos principios, una vez alcanzado un determinado nivel de protección de los derechos sociales, económicos y culturales, la amplia potestad de configuración del legislador en la materia se ve reducida, y en esa medida todo retroceso frente al nivel de protección alcanzado debe presumirse en principio inconstitucional, y por ello está sometido a un control judicial estricto. (30 mar. 2012, J. C. Henao).

Más allá del contenido con que pueda dotarse un régimen de transición en materia pensional, es claro que el estatuido en el artículo 36 de la Ley 100 de 1993, como institución jurídica, fue una conquista que en materia de seguridad social será políticamente inconveniente y jurídicamente inviable ignorar en las reformas pensionales posteriores a dicha ley. No obstante ello, la expedición de la Ley 797 de 2003 demostró años después que los mencionados regímenes de transición pensional, por olvido o por desidia legislativa, efectivamente pueden ser omitidos en las nuevas leyes pensionales.

No se hace alusión aquí al específico régimen de transición contenido en el artículo 36 de la Ley 100 de 1993, sino precisamente al dispositivo normativo de "régimen de transición", cualquiera sea la norma pensional en la que se le consagre.

De esta manera, queda claro que la omisión legislativa consistente en la no inclusión de un régimen de transición en la Ley 797 de 2003 
significa una medida regresiva en comparación con la situación legal alcanzada en la Ley 100 de 1993, norma que en efecto estableció un régimen de transición. Bajo esta concepción, la figura normativa del régimen de transición ostenta la naturaleza jurídica de garantía a favor de los afiliados al sistema pensional, sin perjuicio de los futuros criterios que el legislador considere tener en cuenta al momento de desarrollarlo.

Por ende, la obligatoriedad en el establecimiento de un régimen de transición en toda reforma jurídica que afecte el derecho a la pensión de vejez en el régimen de prima media con prestación definida implica que la libertad de configuración legislativa queda legítimamente condicionada en el sentido de respetar unos límites mínimos -el establecimiento de un régimen de transición-, sin cuya consagración, precisamente, se incurre en medidas regresivas en materia de seguridad social pensional, contrariando el principio de la progresividad que rige este trascendental campo jurídico.

\section{B. La omisión legislativa relativa en la no inclusión de régimen de transición en la Ley 797 de 2003}

En esta instancia del presente discurrir jurídico cabe cuestionar si la no inclusión de un régimen de transición en una reforma pensional tiene la potencialidad de constituirse en una omisión legislativa que, a su vez, sea fundamento de una acción de inconstitucionalidad. El abordaje de este aspecto debe necesaria- mente hacerse a la luz de los principios que informa el Sistema General de Pensiones, entre los que se encuentra el principio de progresividad.

A la luz del principio de progresividad ha de tenerse en cuenta que los niveles mínimos alcanzados en materia de seguridad social en pensiones se constituyen en parámetros y logros frente a los cuales las nuevas normas jurídicas que se establezcan, cuando menos, deben mantenerlos.

Analizada bajo estos parámetros la institución del régimen de transición en pensiones, se deduce que dicho dispositivo legal constituye una garantía para los afiliados frente a las reformas pensionales que modifiquen aspectos sustanciales relacionados con el derecho a la pensión de vejez en el régimen de prima media con prestación definida. Y es que, precisamente, toda reforma pensional, en principio, es la manifestación de una política pública estatal que en materia de derechos sociales prestacionales se verá reflejada en la situación de un grupo poblacional que, como la tercera edad, merece especial protección del Estado, convirtiéndose esta temática en un asunto de especiales connotaciones constitucionales.

Ahora bien, en relación con los elementos que permitirían formular pretensiones de inconstitucionalidad en contra de la reforma pensional introducida por la Ley 797 de 2003 con ocasión de la ausencia de régimen de transición, se hace necesario analizar dicha situación desde la doctrina decantada por la Corte Cons- 
titucional colombiana, sintetizada en la Sentencia C-767 de 2014 sobre la institución de la inconstitucionalidad por omisión legislativa relativa:

La jurisprudencia constitucional resalta, igualmente, que la declaratoria de omisión legislativa relativa está precedida de requisitos definidos, que responden a la necesidad de preservar el principio democrático, el cual sustenta la libertad de configuración normativa de que es titular el legislador. En este sentido, el precedente en comento ha sistematizado los requisitos que deben concurrir para que se declare la inconstitucionalidad de un precepto en razón de la omisión legislativa relativa. Así, es necesario que, “(i) que exista una norma sobre la cual se predique necesariamente el cargo; (ii) que la misma excluya de sus consecuencias jurídicas aqueIlos casos que, por ser asimilables, tenían que estar contenidos en el texto normativo cuestionado, o que el precepto omita incluir un ingrediente o condición que, de acuerdo con la Constitución, resulta esencial para armonizar el texto legal con los mandatos de la Carta; (iii) que la exclusión de los casos o ingredientes carezca de un principio de razón suficiente; (iv) que la falta de justificación y objetividad genere para los casos excluidos de la regulación legal una desigualdad negativa frente a los que se encuentran amparados por las consecuencias de la norma; y (v) que la omisión sea el resultado del incumplimiento de un deber específico impuesto por el constituyente al legislador. (16 oct. 2014, J. I. Pretelt).
Visto el discurrir del máximo tribunal constitucional colombiano respecto de la institución de la inconstitucionalidad por omisión legislativa relativa, es pertinente señalar que, en efecto, la no inclusión de un régimen de transición para la pensión de vejez en la reforma introducida a la Ley 100 de 1993 mediante la Ley 797 de 2003, hace viable la tesis jurídica consistente en que esta última norma es plausible de ser demandada y, en consecuencia, declarada de inconstitucional en consideración a las siguientes razones:

- Existe una norma jurídica de la cual predicar el cargo de inconstitucionalidad por omisión legislativa relativa, que para el presente caso está constituida por la Ley 797 de 2003.

- Al guardar coherencia el régimen de transición pensional de la Ley 100 de 1993 con los preceptos constitucionales de la progresividad de los derechos, los mandatos de la Carta constitucional colombiana permiten colegir que toda reforma pensional relativa a la pensión de vejez en el régimen de prima media con prestación definida, en virtud de los principios de proporcionalidad y razonabilidad, necesariamente debe prever la existencia de un régimen de transición, so pena de tornarse en arbitraria.

- En efecto, la no inclusión de régimen de transición respecto de la pensión de vejez en la Ley 797 de 2003 carece de un principio de razón suficiente que justifique dicha omisión. 
- En la hipótesis aquí expuesta, la falta de justificación y objetividad que eventualmente hubieren fundamentado la omisión del régimen de transición predicable de la Ley 797 de 2003, genera, en abstracto, para los sujetos que hubiesen sido beneficiarios del hipotético régimen de transición, una desigualdad negativa respecto de los "nuevos afiliados" al sistema pensional, esto es, quienes lo hicieron con posterioridad a la vigencia de la Ley 797 de 2003. Ello por cuanto ubica a estas dos categorías de destinatarios de las normas en una misma situación jurídica, al no establecer a favor del primer grupo ningún régimen de transición, lo que desde el ámbito constitucional se justifica y hace necesario en todo tránsito legislativo que implique la afectación del núcleo esencial de un derecho fundamental, como sería en el presente caso el derecho irrenunciable a la seguridad social pensional.

- La no inclusión de un régimen de transición pensional en la reforma introducida a la Ley 100 de 1993 mediante la Ley 797 de 2003, evidentemente resulta en el incumplimiento de un deber específico impuesto por el Constituyente al legislador colombiano, teniendo en cuenta que del análisis armónico de los artículos $48^{\circ}$ y $53^{\circ}$ de la Constitución Política de Colombia de 1991 se puede colegir, sin hesitación alguna, que el establecimiento de un régimen de transición, en tratándose de reformas pensionales, se convierte en un dispositivo legal mediante el cual se reconoce la protección jurídica de las denominadas expectativas legítimas.

Paralelamente a las anteriores consideraciones es necesario plantear la hipotética situación jurídica existente en el evento en que, previa la tramitación de una acción pública de inconstitucionalidad por omisión legislativa relativa en contra de la Ley 797 de 2003, con motivo de la no inclusión de régimen de transición alguno respecto de los afiliados al Sistema de Pensiones amparados por el régimen de prima media con prestación definida, la honorable Corte Constitucional decidiera declarar la inconstitucionalidad de la referida Ley 797 de 2003 por omisión legislativa relativa. En tal caso, sería previsible que la decisión de dicho órgano judicial estuviera encaminada a instar al legislador colombiano a establecer el mencionado régimen de transición o, en su defecto, $y$ atendidos ciertos precedentes jurisprudenciales relacionados con la materia, ${ }^{3}$ no sería extraño que la propia Corte Constitucional fijara los criterios que, desde sus particulares consideraciones jurídicas, debería contener el régimen de transición pensional que no existió en la Ley 797 de 2003.

3. Téngase en cuenta que en aras de resolver la situación jurídica de ciertos afiliados al régimen de prima media con prestación definida que cesaban en ser beneficiarios del régimen de transición previsto en el artículo 36 de la Ley 100 de 1993 por haberse afiliado al régimen de ahorro individual con solidaridad, la honorable Corte Constitucional en Sentencia T-462-2003 fijó la regla consistente en que si el afiliado al régimen de prima media con prestación definida "perdía" el derecho al régimen de transición por haberse trasladado de régimen pensional, igualmente estaba en posibilidad de "recuperarlo" en cualquier tiempo bajo la condición de que al primero de abril de 1993 tuviere cotizados al sistema 15 años o 750 semanas. 
Y es que esa omisión legislativa, consistente en la no inclusión de régimen de transición pensional en la Ley 797 de 2003, sigue produciendo efectos al día de hoy, puesto que dicha ley estableció, por omisión, unas condiciones pensionales más gravosas para los afiliados al sistema pensional regidos por la Ley 100 de 1993, en el período comprendido entre el primero $\left(1^{\circ}\right)$ de abril de 1994, y quienes antes de la entrada en vigencia de la Ley 797 de 2003 tenían unas legítimas expectativas de consolidar su derecho pensional por el riesgo de vejez con el cumplimiento de una densidad de mil (1000) semanas cotizadas. Estas expectativas fueron, de manera tajante, unilateral e inopinada, modificadas mediante la expedición de la Ley 797 de 2003, norma que, como precedentemente se expuso, no consagró ninguna clase de régimen de transición para los afiliados al régimen de prima media con prestación definida.

\section{CONCLUSIONES}

Tomando como referente la jurisprudencia decantada de la Corte Constitucional en torno al régimen de transición establecido en el artículo 36 de la Ley 100 de 1993, surge para los afiliados al régimen de prima media con prestación definida el derecho a que en toda reforma pensional sucesiva que afecte el núcleo esencial de la pensión de vejez se establezca un régimen de transición pensional que si bien es cierto, en principio, necesariamente no comprenderá ni beneficiará a todos los afiliados al sistema, también es cierto que favore- cerá a todos aquellos de quienes se predique la existencia de unas expectativas legítimas de aspirar a consolidar el derecho a la pensión de vejez, bajo el amparo de las normas que regían al momento de su afiliación pensional al sistema bajo el régimen de prima media con prestación definida.

Al respecto ha de diferenciarse, entonces, el derecho subjetivo al régimen de transición que cobija a un número específico de afiliados al sistema pensional, del derecho abstracto al establecimiento de un régimen de transición en toda reforma pensional del régimen de prima media, derecho este que ya no haría parte del derecho individual del afiliado, sino que se constituye en un derecho económico, social y cultural de carácter prestacional, cuya titularidad radica en el grupo poblacional de los afiliados al sistema pensional, e indirectamente en los potenciales beneficiarios de dichos afiliados.

Estudio aparte merece la problemática consistente en establecer los criterios de inclusión y exclusión a tener en consideración en el mencionado régimen de transición, lo mismo que el problema jurídico de determinar a partir de qué momento los afiliados al sistema pensional del régimen de prima media con prestación definida del originario régimen de transición establecido en el artículo 36 de la Ley 100 de 1993 pasaron de tener unas meras expectativas, a unas expectativas legítimas en relación con la adquisición de su pensión de vejez. Lo anterior no obsta para que, a título de conclusión, se expongan unas específicas consideraciones 
que pueden dar origen a ulteriores indagaciones en este campo de la seguridad social.

Para ello, cabe traer a colación la filosofía jurídica prohijada por la Corte Constitucional en la línea jurisprudencial que en el ámbito del régimen de transición ha elaborado bajo los siguientes lineamientos contenidos en la Sentencia C-663 de 2007:

Los regímenes de transición en el ámbito pensional han sido entendidos como mecanismos de protección previstos por el legislador, mediante los cuales se pretende que los cambios introducidos por una reforma normativa no afecten excesivamente a quienes tienen una expectativa próxima de adquirir un derecho, por estar cerca del cumplimiento de los requisitos necesarios para acceder a él, en el momento del cambio legislativo.

La consagración de tales regímenes, le permite al legislador ir más allá de la protección de los derechos adquiridos de las personas, para salvaguardar incluso ‘las expectativas de quienes están próximos por edad, tiempo de servicios o número de semanas cotizadas a adquirir el derecho a la pensión de vejez, lo que corresponde a una plausible política social que en lugar de violar la Constitución, se adecua al artículo 25 [de la Carta] que ordena dar especial protección al trabajo.

Los regímenes de transición, en consecuencia, (i) recaen sobre expectativas legítimas de los asociados y no sobre derechos adquiridos; (ii) su fundamento es el de salva- guardar las aspiraciones de quienes están cerca de acceder a un derecho específico de conformidad con el régimen anterior y (iii) su propósito es el de evitar que la subrogación, derogación o modificación del régimen anterior, impacte excesivamente las aspiraciones válidas de los asociados, especialmente si existe la posibilidad de minimizar esa incidencia y de armonizar las expectativas ciudadanas y los cambios legislativos a través de un régimen de transición. (29 ago. 2007, M. J. Cepeda). [Cursivas añadidas].

Desde la entrada en vigencia de la Ley 100 de 1993 en materia pensional -que lo fue a partir del 1 de abril de 1994 para el sector privado, y desde 30 de junio de 1995 para el sector público-, hasta la entrada en vigencia de la Ley 797 de 2003, la cual inició el 29 de enero de 2003, transcurrieron ocho años y diez meses en el caso del sector privado, y siete años y siete meses en el caso del sector público, tiempo frente al cual cabe cuestionarse si efectivamente alcanzó a consolidarse una expectativa legítima de los afiliados al sistema en relación con lograr la pensión de vejez con un mínimo de 1000 semanas cotizadas.

Para responder la anterior pregunta se hace necesario calcular la densidad de semanas cotizadas que en uno y otro caso, respectivamente, lograría acreditar un afiliado al Sistema General de Pensiones. Tomando como base los 365 días del año y los siete días que conforman cada semana, cada año cotizado arroja un aproximado de 52 semanas, obteniéndose, para el caso del sector privado, un total de 458 
semanas bajo el entendido de que el afiliado hubiera iniciado cotizaciones al sistema pensional desde el 1 de abril de 1994 y las hubiera mantenido hasta el 29 de enero de 2003 , fecha de entrada en vigencia de la Ley 797 de 2003.

Pues bien, sí dicha persona ha sufragado lo que puede considerarse aproximadamente la mitad -458 semanas- de la densidad mínima de semanas requeridas -1000 semanaspara acceder a la pensión de vejez que originariamente exigía la Ley 100 de 1993, podría decirse que dicho sujeto se encuentra "próximo" a pensionarse en razón de la densidad de semanas cotizadas al sistema, puesto que ha acreditado aproximadamente el cincuenta por ciento (50\%) de las semanas requeridas y tiene por tanto una expectativa legítima al respecto.

Partiendo de esta valoración, existen entonces suficientes razones para afirmar que la Ley 797 de 2003 debió haber establecido un régimen de transición para los afiliados al régimen de prima media con prestación definida del Sistema General de Pensiones que se afiliaron a partir del 1 de abril de 1994, en tratándose de trabajadores del sector privado.

Si se toman en consideración los criterios utilizados en el artículo 36 de la Ley 100 de 1993 para establecer los beneficiarios de dicho régimen de transición, se concluye que en él se consideró como personas "próximas a pensionarse" a aquellos afiliados a los cuales les faltaban hasta veinte años para alcanzar la edad mínima de pensión, puesto que el porcentaje mayoritario de sus beneficiados fueron las mujeres que para el 1 de abril de 1994 tuviesen 35 años o más de edad, y los hombres que para idéntica fecha contaran con 40 años o más de edad. Lo anterior, comparado con las condiciones de edad exigidas por el Acuerdo 049 de 1990, permite concluir que los sujetos en cuyo beneficio se estableció el régimen de transición, debían, en efecto, aguardar hasta la edad mínima de 55 años -las mujeres y 60 años - los hombres-, a efectos de acceder a la prestación económica vitalicia por el riesgo de vejez, sin perjuicio de las exigencias que en cuanto a densidad de semanas mínimas cotizadas establecía el mencionado Acuerdo 049 de 1990.

Del análisis precedente es dable concluir que por tratarse de un derecho de carácter social como lo es el derecho a la seguridad social en pensiones, los afiliados al sistema tendrán derecho, en virtud del principio de la seguridad jurídica, a que en toda reforma pensional se consagre un régimen de transición que salvaguarde las expectativas legítimas de aquellos afiliados que al momento de entrar a regir la nueva ley pensional se encontraban próximos, por edad, o por densidad de semanas cotizadas, a consolidar su derecho irrenunciable a ser beneficiarios de la pensión de vejez.

Ahora bien, determinar en qué circunstancias y bajo qué criterios se considera que un afiliado está "próximo" a alcanzar su derecho a la pensión de vejez es un aspecto que implica valoraciones filosóficas, sociológicas y juicios de valor respecto de los cuales se hace necesario 
realizar un complejo análisis que no se limite a lo jurídico, sino que también indague aspectos extrajurídicos (D`Agostino, 2007, p. 219), como los relacionados con la expectativa de vida, las tasas de desempleo en las distintas regiones de Colombia, el nivel de cualificación laboral del afiliado, entre otros factores ${ }^{4}$ que necesariamente inciden al momento de valorar la "proximidad" o "lejanía" de un afiliado para obtener el derecho a la pensión de vejez.

En un contexto laboral como el colombiano, el hecho de que un trabajador que no ha recibido cualificación técnica ni universitaria y cuyos ingresos laborales ordinarios están constituidos por un salario mínimo alcance a cotizar, verbigracia, la suma de 500 semanas al Sistema General de Pensiones, necesariamente debe analizarse con criterios distintos a los aplicados frente a un empleado cualificado, de ingresos económicos mensuales superiores al salario mínimo legal mensual vigente y que ostente idéntica densidad de semanas cotizadas, puesto que las probabilidades de ocupación y permanencia en el mercado laboral de uno y otro sujeto evidentemente son distintas. ${ }^{5}$
Así las cosas, para este caso hipotético se podría aseverar que en Colombia, sin duda alguna, el logro de 500 semanas cotizadas por parte de un trabajador que históricamente ha devengado un salario mínimo, lo acerca más a la pensión de vejez en comparación con un empleado profesionalmente cualificado, para quien cumplir 500 semanas cotizadas quizás no sea tan dificultoso; además, dicho sea de paso, con el solo hecho de afiliarse y cotizar al Sistema General de Pensiones ya ha logrado superar la informalidad y la desprotección laboral que, según las cifras suministradas periódicamente por la autoridad pública de estadística y difundidas por los medios de comunicación, afectan a un alto porcentaje de la población económicamente activa del país.

Se concluye entonces que si bien es cierto que desde el ámbito constitucional colombiano no se encuentra positivamente establecida la obligación en cabeza del legislador colombiano de establecer regímenes de transición en las reformas pensionales que se efectúen en el régimen de prima media con prestación definida, también es cierto que en virtud de los

4. Precisamente, son tan variados los factores que inciden en la consolidación de un número mínimo de semanas cotizadas, que en el año 2015 se radicó en la Cámara de Representantes, para el respectivo trámite, el proyecto de ley número 049 de 2015 mediante el cual se pretende modificar el numeral 2 del artículo 33 de la Ley 100 de 1993 con el objetivo de establecer que en el régimen de prima media del Sistema General de Pensiones se deberá "haber cotizado un mínimo de mil ciento cincuenta (1150) semanas si es mujer o mil trescientas (1300) semanas si es hombre” (Gaceta del Congreso 562, 2015, p. 1).

5. Al respecto es pertinente hacer referencia a los criterios normativos establecidos en el Programa de Subsidio al Aporte en Pensión (PSAP) para que un afiliado al sistema pensional sea acreedor de los beneficios emanados de la subcuenta de solidaridad del Fondo de Solidaridad Pensional (FSP) creado mediante el artículo $25^{\circ}$ de la Ley 100 de 1993 . Los beneficiarios de este subsidio de la cotización mensual a pensión serán las personas cuyos ingresos sean iguales o inferiores a un salario mínimo mensual legal vigente, que por condiciones específicas no estén en la capacidad de realizar el aporte total a pensión, tales como: trabajadores independientes del sector rural y urbano, madres sustitutas del ICBF, personas en situación de discapacidad, desempleados y concejales de municipios de categorías 4, 5, y 6. Véase: https://colombiamayor.co/pdf/ PSAP_plegable_2015.pdf 
principios de la seguridad jurídica, la proporcionalidad, la razonabilidad y la progresividad en materia de derechos económicos, sociales y culturales, se hace imperativo su establecimiento en toda reforma pensional que afecte las condiciones para la causación del derecho a la pensión de vejez, incluida la Ley 797 de 2003.

Sobre la utilidad o no utilidad de una declaratoria de inconstitucionalidad de la Ley 797 de 2003 a título de omisión legislativa relativa por no consagrar régimen de transición alguno respecto a los afiliados al Sistema General de Pensiones que empezaron a consolidar sus expectativas a la pensión de vejez bajo las premisas de la Ley 100 de 1993, deberían recaer ulteriores análisis jurídicos, sin que para ello sea impedimento los más de doce años que han transcurrido desde la entrada en vigencia de la Ley 797 de 2003. De llegar a ser ordenado el establecimiento de un régimen de transición pensional en esta norma, surgirían dificultades inherentes al establecimiento de un régimen de transición de carácter retroactivo, análisis que desborda el contenido del presente artículo.

Por último, queda claro que toda reforma pensional que se realice al Sistema General de Pensiones (Ley 100 de 1993) y que modifique los requisitos sustanciales para que los afiliados sean beneficiarios de la pensión de vejez, desde la óptica del principio de la progresividad plasmado en el artículo 53 de la Constitución Política de 1991 debe contar con un régimen de transición. Proceder de otra manera resulta regresivo y contraviene la garantía de los dere- chos económicos, sociales y culturales en plena vigencia en el actual Estado social de derecho que rige en Colombia. Ello no significa, per se, que el principio de la progresividad en materia de seguridad social sea absoluto, puesto que como bien ha señalado senda jurisprudencia de la Corte Constitucional, dicho principio debe ser matizado en cada caso concreto.

\section{Referencias}

1. D'Agostino, F. (2007). Filosofía del derecho. Bogotá: Editorial Temis/Universidad de La Sabana.

2. Congreso de la República. (5 de agosto de 2015). Proyecto de ley 049 de 2015 Cámara. Gaceta del Congreso 562.

3. Jaramillo, I. (2013). Traslados y recuperación del régimen de transición pensional en la jurisprudencia laboral. Bogotá: Legis Editores S. A.

4. Kelsen, H. (2010). Teoría pura del derecho. Bogotá: Libros Hidalgo.

5. Montoya Osorio, M. y Montoya Pérez, G. (2001). Las personas en el derecho civil colombiano. Bogotá: Editorial Leyer.

6. Nieto, L. (2011). La interpretación de las normas jurídicas. Bogotá: Editorial Temis.

7. Ossorio, M. (1999). Diccionario de Ciencias Jurídicas, Políticas y Sociales. Buenos Aires: Editorial Heliasta. 
8. Corte Constitucional. Sentencia C-789 de 2002. (M. P. Rodrigo Escobar Gil: septiembre 24 de 2002).

9. Corte Constitucional. Sentencia T-462 de 2003. (M. P. Eduardo Montealegre Lynett: junio 5 de 2003).

10. Corte Constitucional. Sentencia C-754 de 2004. (M. P. Álvaro Tafur Galvis: agosto 10 de 2004).

11. Corte Constitucional. Sentencia C-663 de 2007. (M. P. Manuel José Cepeda Espinoza: agosto 29 de 2007).

12. Corte Constitucional. Sentencia T-168 de 2009. (M. P. Humberto Antonio Sierra Porto: marzo 18 de 2009).

13. Corte Constitucional. Sentencia C-228 de 2011. (M. P. Juan Carlos Henao Pérez: marzo 30 de 2011).
14. Corte Constitucional. Sentencia T-754 de 2012. (M. P. Jorge Ignacio Pretelt Chaljub: septiembre 26 de 2012).

15. Corte Constitucional. Sentencia C-853 de 2013. (M. P. Mauricio González Cuervo: noviembre 27 de 2013).

16. Corte Constitucional. Sentencia C-767 de 2014. (M. P. Jorge Ignacio Pretelt Chaljub: octubre 16 de 2014).

17. Corte Suprema de Justicia. Sala de Casación Laboral. Sentencia del 15 de febrero de 2011. (M. P. Carlos Ernesto Molina Monsalve). Radicación número 40662.

18. Corte Suprema de Justicia. Sala de Casación Laboral. Sentencia de 25 de julio de 2012. (M. P. Carlos Ernesto Molina Monsalve y Luis Gabriel Miranda Buelvas). Radicado número 38674. 